\title{
Cooperation, Competition, and Ties That Bind
}

\author{
Zack Dumont
}

$\mathrm{C}$ ooperation and competition are often considered at odds with one another. A person's desire to cooperate with others may hinder the drive to compete, and vice versa. There are also matters of context and scale: perhaps when the stakes are low, a friendly competitive streak emerges in someone who would usually aim to get along with others. As long as intentions are true, both approaches have merit. After all, competition is considered an important — perhaps the most important—driver of innovation. Conversely, when it comes to getting big things accomplished, cooperation has afforded humanity great success.

Topical debates about markets and social justice aside, I urge you to consider current proportions of competition and cooperation in our world. On a global level, I see relentless competition for everyone's emotion, time, money, energy, votes, and more. Cooperation is rarely modelled, and hardly encouraged. Unbridled competition may be driving us apart. Where is the balance?

I do not mean to present a false dichotomy. As is often the case, in reality there are shades of grey, pros and cons, and perspective is paramount. In an editorial elsewhere in this issue, Bresee tackles the interpretation of $p$ values in research (Can J Hosp Pharm. 2019;72[5]:339-40). We're reminded that $p$ values continue to be used to create dichotomies for consumers of scientific literature-put simply, "yes, an intervention is beneficial", or not. The editorial compares and contrasts opposing philosophies presented in 2 recent publications: the first highlighting the ineffectiveness and dangers of the $p$ value's arbitrary cutoff, the other leaning on this cutoff as a natural mechanism in health care decision-making. Both arguments are compelling. Rather than taking sides, Bresee finds common ground, and a unified position emerges. The competition drove our understanding deeper, and the cooperation found something greater. In health care, opinions and positions abound. When we challenge the notion that they are at odds with one another, using empathy to come together, we rise above the differences, and patients will stand to benefit. It's the more challenging road, but patients deserve it.
Also in this issue of the journal, we learn more about Canada's First Nations population, for whom the health care community has designed a mismatched medication reconciliation process ( $\mathrm{Can}$ J Hosp Pharm. 2019;72 [5]:403-6). Thankfully, the author, Swidrovich, shares practical solutions to facil-

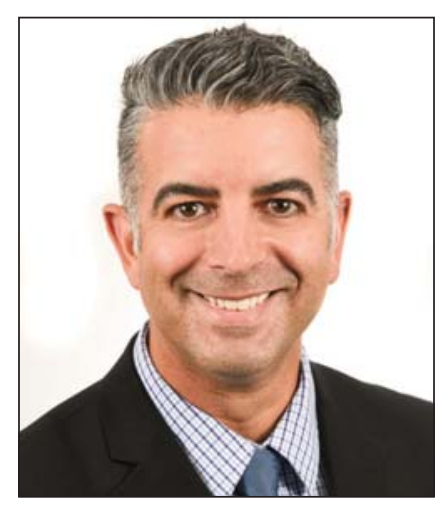
itate leadership efforts by front-line pharmacists. The article reminds me of the commitment that the Canadian Society of Hospital Pharmacists (CSHP) made in October 2018, to address the Truth and Reconciliation Commission report. In the coming months, CSHP staff and volunteers will put aside competition and will cooperate with other organizations to produce something bigger than any strategic plan, balanced score card, or bottom line.

I see these efforts as signs that health care providers will shrug off global trends, strive to expand circles of cooperation (in both size and number), and shrink domains in which nonproductive, potentially harmful competition persists. CSHP is our forum for coming together, and there is no more fitting circle to represent your unique professional interests. Given the modern imbalance of competition to which I alluded earlier, let's go all-out in opting for cooperation. Encourage others to join us.

Together, we'll cooperate. We'll compete, not among ourselves, but with disease and inequality. We'll fight to see things from others' perspectives. We'll find the ties that bind.

Zack Dumont, BSP, ACPR, MS(Pharm), became President Elect and Internal Liaison for the Canadian Society of Hospital Pharmacists at the Board meeting following his election during the Annual General Meeting in October 2019. 